\title{
Efficacy of TLE Regimen in Prevention of Mother to Child Transmission of HIV
}

\author{
Dr.S.Sumithra ${ }^{1}$,Dr R.Manonmani ${ }^{2}$ \\ ${ }^{1}$ Assistant Professor, ${ }^{2}$ Associate Professor \\ Department Of Obstetrics And Gynecology,Government Coimbatore Medical College Hospital \\ The TamilnaduDr.MGR Medical Unversity,India
}

\begin{abstract}
:
Aim: To Evaluate the efficacy of TLE regimen in prevention of mother to child transmission of HIV.Method: All women who tested positive for HIV and delivered between August 2013 to May 2015 were included in the study and was started on TLE regimen(Tenofovir 300mg,Lamuvidine 300mg, Efavirenz 600mg)at the earliest AN visit, and continued thereafter lifelong.The baby was started on syrup Nevirapine $2 \mathrm{mg} / \mathrm{Kg}$ for 6 weeks of life and 12 weeks if the mother was started on ART later than 12 weeks of gestation.The infants were tested for HIV with PCR at 6 weeks, 6 months, 12 months and 18 months.Results: Of the 91 live births, 6 infants died in the neonatal period. Of the 74 babies followed up 5 tested positive for HIV and 69 were negative. The transmission rate of HIV was $6.7 \%$ and the efficacy of TLE regimen was 93.2\%.Conclusion:The risk of transmission of HIV from mother to child had declined with the use of combination ART and the emergence of drug resistance was reduced.
\end{abstract}

Keywords: ART,PPTCT,TLEregimen,Nevirapine

\section{Introduction}

India has an estimated HIV prevalence of $0.26 \%$ in adults and $6.54 \%$ in children less than 15 years [1].Mother to child transmission remains the second commonest mode of transmission of HIV.Women account for around one million out of 2.5 million estimated number of people living with HIV.The seroprevalence of HIV in pregnant women attending public hospital were reported to be $0.5-3.3 \%$ in this country [2]. The rising prevalence of HIV among pregnant women in India is of concern,Perinatal transmission accounts for about $4 \%$ of total HIV infection in India [3]. Early testing of Antenatal mother, administration of antiretroviral therapy,institutional delivery,follow up and administration of ART to the infant and contraception are critical for prevention of mother to child transmission of HIV.

\section{Methods}

Women who delivered at Government Coimbatore Medical College hospital between August 2013May 2015 and tested positive for HIV were included in the study. All patients were counseled and started on TLE regimen (Tenofovir $300 \mathrm{mg}$, lamuvidine 300mg, Efavirenz 600mg) on registration at the AN clinic and continued throughout pregnancy,postpartum and lifelong thereafter.Infant was given syrup nevirapine $2 \mathrm{mg} / \mathrm{kg}$ and continued for 6 weeks if the mother was started on ART within 12 weeks of gestation.If the ART was started more than 12 weeks of gestationnevirapine continued upto12 weeks of life. LSCS was done for obstetric indications. Mother counseled advised on choice of alternative feeds and breast feeds.Infants were tested with PCR for HIV at 6 weeks, 6 months, 12 months and 18 months of life.

\section{Results}

The total deliveries occurred in the period between August 2013 and May 2015 was 11,635. Of those women who tested positive for HIV and delivered during the same period was 91. The incidence of HIV in pregnant mothers was $0.7 \%$. The spouse of patients were counseled and tested for HIV. Of which 66(72.5\%) tested positive, $18(19.7 \%)$ were negative,7(7.6\%) were not tested.

The youngest women tested positive for HIV was aged 17 years and eldest was 38 years. The mean age of the study group was 24.9 years with majority belonging to the age group between 21 to 25 years. The average weight of infants delivered was $2.4 \mathrm{kgOf}$ the 91 delivered, 51(56\%) was by LSCS and 40(43.9\%) by vaginaldelivery. Of the 91 live births, six babies died in the neonatal period. Three were due to Low birth weight and RDS, 2 were due to ADD, in one the cause was not known.Since these women hailed from various districts, and shifted to their native places 11 babies lost follow up. Out of the 74 infants followed, 5 tested positive for HIV and 69 tested negative at the end of 18 months. Of the 5 positive infants, 2 tested positive at 6 weeks, 2 at 6 months and 1 at one yearof age. 69 babies werefound to be negative. 


\section{Discussion}

Mother to child transmission of HIVcan occur in antenatal especially in the later part of pregnancy,intrapartumand postpartum. The prevalence of HIV in antenatal women has been used to monitor trends in the general population and to predict the seroprevalence in young children[4].The pregnant women should be offered universal screening because appropriate interventions with early initiation of ART can reduce mother to child transmission (MTCT).Intrapartum events are important in governing MTCT since this is the period where the risk is highest.

The use of combination ART avoids the problem of low efficacy and emergence of higher rates of viral resistance associated with the use of single dose nevirapine[5].Highly active antiretroviral therapy (HAART) has reduced the vertical transmission rates to around 1- $2 \%$ [3].Combination ART are well tolerated except few GI side effects, hyperglycemia, elevated transaminases.

Our study had an efficacy of $93.7 \%$ in prevention of vertical transmission of HIV since the administration of TLE regimen to the ANmother was started in early pregnancy and continued postpartum along with syrup nevirapine to the baby. The transmission rate of HIV in our study was $6.4 \%$. The HAART therapy has reduced the MTCT to $1.2 \%$ [7]. There is a risk of LBW infant and preterm birth, IUGR with combination ART. The mean weight of infants in our study group was $2.4 \mathrm{~kg}$.

Breastfeeding is an important route of HIV transmission from mother to child which accounts for up to $20 \%$ but where safe feeding alternatives are not available, finding ways to avoid transmission through breast feeding remains an issue of critical importance[6]. Of the 91 infants 67 were breast fed and 7 were on alternative feeds. Of the 5 infants tested positive 3 were on alternative feeds and 2 on breast feeds. Triple drug ART throughout pregnancy and sypnevirapine for the infant postpartum makes breast feeding safe and feasible in a low resource-limited setting.

Tables

Table .1Distribution of HIV positive mother according to age

\begin{tabular}{|c|c|}
\hline Range of age in years & No of mothers \\
\hline$>20$ & 6 \\
\hline $21-25$ & 53 \\
\hline $26-30$ & 21 \\
\hline $31-35$ & 9 \\
\hline$>35$ & 2 \\
\hline
\end{tabular}

Table 2.Rate of transmission of HIV and Efficacy of multidrug ART:

\begin{tabular}{|c|c|c|c|c|}
\hline $\begin{array}{l}\text { No of infants } \\
\text { followed up }\end{array}$ & $\begin{array}{l}\text { No of infants } \\
\text { tested positive }\end{array}$ & $\begin{array}{l}\text { No of infants tested } \\
\text { negative }\end{array}$ & $\begin{array}{l}\text { Perinatal } \\
\text { transmission }\end{array}$ & $\begin{array}{l}\text { Efficacy } \\
\text { of } \\
\text { Multidrug } \\
\text { ART }\end{array}$ \\
\hline 74 & 5 & 69 & $6.7 \%$ & $93.2 \%$ \\
\hline
\end{tabular}

Table 3.Cause of Neonatal Death

\begin{tabular}{|l|c|}
\hline \multicolumn{1}{|c|}{ Cause of death } & Number \\
\hline Acute diarrheal disease & 2 \\
\hline LBW/Preterm/RDS & 3 \\
\hline unknown & 1 \\
\hline
\end{tabular}

Table 4.Characteristics of HIV positive babies

\begin{tabular}{|c|l|l|l|c|}
\hline Infant & Mode of delivery & $\begin{array}{l}\text { Feeding } \\
\text { practices }\end{array}$ & Spouse status & $\begin{array}{l}\text { GA at start of ART } \\
\text { in weeks }\end{array}$ \\
\hline 1 & Vaginal & alternative & Reactive & 12 \\
\hline 2 & Vaginal & alternative & Non reactive & 24 \\
\hline 3 & Vaginal & Breast feeding & Not tested & 18 \\
\hline 4 & LSCS & Breast feeding & Reactive & 11 \\
\hline 5 & LSCS & alternative & Reactive & 12 \\
\hline
\end{tabular}

Table 5.Mode of delivery of followed up infants

\begin{tabular}{|l|c|c|c|c|}
\hline \multirow{2}{*}{$\begin{array}{l}\text { Mode of } \\
\text { delivery }\end{array}$} & \multicolumn{2}{|c|}{ Non reactive infants } & \multicolumn{2}{c|}{ Reactive infant } \\
\cline { 2 - 5 } & Number & $\%$ & Number & $\%$ \\
\hline LSCS & 49 & 66.2 & 2 & 4.08 \\
\hline Vaginal & 37 & 50 & 3 & 8.1 \\
\hline
\end{tabular}

\section{Conclusion}




\section{Conclusion}

It is indeed ironical that HIV infection-a forerunner of death and pregnancy-the origin of new life should coexist often. It is imperative that every HIV infected pregnant women should get access to proper care throughout her course of pregnancy and every effort should be made to ensure that her child is born free of HIV.

In spite of possible increased risk of preterm birth and Low birth weight babies, combination ART in pregnant women clearly shows clear benefits for maternal health and reduction in perinatal transmission. The tide of emerging drug resistance is reduced with combination ART compared to single dose nevirapine. The management of the pregnant woman with HIV infection has evolved significantly over the past years in light of advancements in drug development and a greater understanding of the prevention of perinatal HIV transmission.The risk of HIV transmission from mother to infant had declined to historically low levels with the use of combination antiretroviral medications.

[1]. NACO annual report (2015)

\section{Reference}

[2]. DamaniaKaizad R, Tank Parikshit D, LalaMamathaM,Recent Trends in Mother To Child Transmission of HIV in Pregnancy,JObstetGynecol India Vol. 60, No. 5 : September / October 2010 pg 395 - 402

[3]. NACO Guidelines for the prevention of mother to child transmission of HIV http://www.naco.nic.in/pmtct.html Accessed on 19-032006. [PubMed]

[4]. Zaba B, Boerma T, White Monitoring the AIDS epidemic using HIV prevalence data among young women attending antenatal clinics: prospects and problems.AIDS. $2000 \mathrm{Jul} 28 ; 14(11): 1633-45$.

[5]. Yuel Veronica Irene1, AndappanArun,Efficacy of Single Dose Nevirapine in Prevention of Mother to Child Transmission of HIV- J ObstetGynecol India Vol. 60, No. 3 : May - June 2010 pg 221-224.

[6]. Burrowes S Infant Feeding, child survival and HIV transmission,HIV In Site's Coverage of the XVI Interntional Aids conference

[7]. Cooper ER, Charurat M, Mofenson L, Hanson IC, Pitt J, Diaz C, Hayani K, Handelsman E, Smeriglio V, Hoff R, Blattner W; Women and Infants' Transmission Study Group Combination antiretroviral strategies for the treatment of pregnant HIV-1-infected women and prevention of perinatal HIV-1 transmission.JAcquir Immune DeficSyndr. 2002 Apr 15;29(5):484-94.. 